\title{
Las mujeres obreras en la industria textil, Lima Metropolitana: 1968-1975¹
}

\section{Female workers in the textile industry, Metropolitan Lima: 1968-1975}

\author{
Liz Magaly Salazar Marín² \\ Universidad Nacional Federico Villarreal. Lima, Perú \\ magalysalazarmarin@gmail.com \\ ORCID 0000-0002-3072-2712
}

Citar como: Salazar, L. (2020). Las mujeres obreras en la industria textil, Lima Metropolitana: 1968-1975. Desde el Sur, 12(1), pp. 79-96.

\section{RESUMEN}

La investigación analiza la relación entre la participación laboral y política de las obreras en la industria textil en Lima Metropolitana durante el periodo 1968-1975. Este artículo tiene como objetivo contribuir a la reconstrucción histórica del mundo laboral de las obreras textiles en tiempos de las reformas que Velasco autodenominó como «revolucionarias». La participación laboral de las obreras textiles permitió crear un valor agregado al producto textil y, por ende, garantizó el abastecimiento de textiles al mercado interno, cuya retribución económica generó la obtención de sus propios ingresos económicos como trabajadoras y resultó de importancia económica para el ámbito industrial y estatal. Por último, en el escenario político la presencia y participación de las obreras textiles se registró en los sindicatos y en las comunidades industriales, como espacios para dinamizar sus propuestas y demandas.

1 El artículo es una versión reelaborada de la tesis de licenciatura presentada en la Universidad Nacional Federico Villarreal en setiembre de 2017.

2 Licenciada en Historia por la Universidad Nacional Federico Villarreal con la tesis sobre mujeres obreras textiles durante el velasquismo. Egresada de la maestría de Género y Desarrollo de la Universidad Nacional Mayor de San Marcos. Ponente en los coloquios de Historia de la Universidad Nacional Federico Villarreal, Universidad Nacional Mayor de San Marcos, Universidad Nacional de Trujillo, Pontificia Universidad Católica del Perú, Lugar de la Memoria, Tolerancia y la Inclusión Social (LUM), Primer Congreso de la Red de Historiadoras Feministas en Chile y en la Universidad Nacional San Agustín. Colaboradora en la ONG Movimiento El Pozo. Ha realizado publicaciones en la revista MOTVS 1, 2 y 3 con los artículos «Las mujeres profesionales a través de la prensa en el velasquismo: 1968-1975» y «Más allá de la reforma agraria. La visibilidad de las mujeres campesinas a través del diario El Comercio: 1968-1975». Fundadora e integrante del colectivo de egresados Historia en Movimiento. 


\section{PALABRAS CLAVE}

Mujeres obreras, industria textil, velasquismo

\section{ABSTRACT}

This paper analyzes the relationship between labor and the political participation of female workers in the textile industry in Metropolitan Lima from 1968 to 1975. The aim is to contribute to the historical reconstruction of the world of work for textile workers during a period of reform which Velasco described as revolutionary. In this context, the participation in the labor market of female textile workers enabled them to generate added value to production, thereby guaranteeing supply to the domestic market while generating their own income as workers, and contributing to the economic significance of the industry at a state level. Finally, on the political stage, female textile workers gained a presence and became active in unions and within industrial communities during the Velasco era.

\section{KEYWORDS}

female workers, textile industry, Velasquismo

\section{Introducción}

Para comprender la participación de las obreras textiles en el periodo velasquista resulta necesario presentar un breve balance de los aportes historiográficos desarrollados previamente. En la historiografía sobre el movimiento obrero y sindical, tradicionalmente se registra la constante participación de la masa obrera masculina como protagonista principal de la movilización y del trabajo en la fábrica. Sus actividades los presentaron como los más calificados, los generadores de mayores ingresos, los que gozaron de una mayor estabilidad laboral y tuvieron mayores oportunidades de ascensos. Se ha excluido la participación y presencia de las obreras en el campo industrial fabril y en el sindical. La carencia de investigaciones desde una perspectiva histórica sobre la situación, dinámica y participación de las obreras en el ámbito industrial, específicamente en el área textil y política, se presenta a nivel nacional y en particular en el espacio de Lima Metropolitana.

Lo ideológico llevó a establecer una serie de cegamientos en el avance académico sobre el movimiento obrero y sindical, a pesar de sus peculiares aportes. Sin duda, este eclipsamiento tiene relación con dos tradiciones ideológicas que han precedido a la investigación histórica, en el Perú y en casi todo el mundo académico. «Los analistas materialistas con su énfasis 
en el impacto del capitalismo sobre las sociedades modernizadas también han sido igualmente problemáticos, puesto que el marxismo tiende a privilegiar la categoría de clase sobre todas las otras» (Guy, 1985, p. 16).

Ante las limitaciones sobre las bases teóricas y el foco de estudio por estar impregnado de lo ideológico y lo androcéntrico, es preciso hacer un recuento breve sobre el origen y el proceso evolutivo de los nuevos giros de escribir la historia, y sobre las bases de los trabajos que respaldan la investigación acerca de las obreras. En la década de 1960, se inició la renovación en las construcciones académicas de las ciencias sociales, que cuestionaron los tradicionales discursos académicos y los postulados innovadores que daban sustento en esos tiempos a la realidad y al contexto social, que no consideraban a las mujeres como actoras sociales.

Los factores que condicionaron la renovación de las ciencias sociales fueron tres. El primero fue el desarrollo de la antropología histórica, que permitió impulsar estudios sobre la familia y los roles sexuales. El segundo fue el desarrollo de la nueva historia, que enfatizó a las representaciones, mentalidades y prácticas cotidianas. Por último, el surgimiento de los estudios de las mujeres renovó la línea de la investigación.

Continuando con el desarrollo de la nueva mirada de las ciencias sociales, a fines de la década de 1970 se iniciaron los estudios de género, caracterizados por ser promovidos por las feministas norteamericanas, pero estar distantes ante la línea política feminista.

Siguiendo con el avance de los estudios de género, en la década de 1980 se presentó el término género como un vocablo neutro y libre de propósitos ideológicos. La teoría de género permitió reconocer las diferentes formas de interpretación, organización y simbolización basadas en las diferencias sexuales en las relaciones sociales y ejercer la crítica al sustento esencialista del feminismo. Sus temas de interés fueron las mujeres en las áreas de trabajo, tanto en la casa como fuera de ella, actividades no concordantes con la «feminidad» construida, sino más indiferenciado, es decir, no en relación con las actividades determinadas por sus roles femeninos tradicionales. Buscó conocer la construcción sociocultural de las ideas sobre los roles sociales de varones y mujeres, así como el origen social de las identidades femeninas-masculinas, la imposición social de los comportamientos subjetivos sobre un cuerpo sexuado y las relaciones de poder. Por último, intentó constituir un campo primario, no único, que permitiera articular el poder.

En el Perú los estudios sobre las mujeres se desarrollaron a mediados de la década de 1970 con Ana María Portugal, Esther Andradi, Violeta Sara-Lafosse y Maruja Barrig. Ellas realizaron los primeros trabajos sobre 
la experiencia femenina, pero como precedente inmediato estuvieron los estudios sobre las mujeres que impulsó el gobierno velasquista, a través de una serie de entidades en lo laboral y educativo. Estos estudios iniciales se caracterizaron por mostrar descripciones y análisis breves sobre las condiciones de trabajo de las mujeres y comparaciones de las estadísticas sectoriales en los censos nacionales, que sirvieron para argumentar el modelo desarrollista basado en la incorporación de la mujer en el proceso económico, con el fin de alcanzar mayores niveles educativos, una mayor capacitación técnica en ellas, a través de la derogación de las leyes laborales que impedía a las mujeres su inserción al trabajo industrial, y la dación de nuevas leyes.

En el Perú, en la década de 1980, la producción académica sobre la situación de las mujeres aumentó y fue más sistematizada. Las razones fueron tres: primero, el impulso de las ONG; segundo, el crecimiento de las organizaciones de mujeres y del movimiento de mujeres; $y$ tercero, el interés de algunas financieras en incorporar a las mujeres en proyectos institucionales.

A pesar de las limitaciones, los estudios de las mujeres y de género desarrollados en el Perú han aportado al ampliar y cuestionar las tradicionales construcciones académicas.

Asimismo, a raíz de la revisión historiográfica de los estudios de las mujeres y de género, y ante la necesidad de continuar con la ilación de trabajos desarrollados en la década de 1980, se registró una labor académica sobre el aspecto laboral de las mujeres en el Perú, que fueron impulsadas por diferentes perspectivas cuyo desarrollo quedó congelado en el tiempo.

Ante ello, se busca la reconstrucción de la historia de las obreras y así romper con la indiferencia que suele impregnarse en los trabajos académicos, que ignoran las experiencias de mujeres, niños, afroperuanos, indígenas, diversidades sexuales, etc. El resultado es una mirada y comprensión limitada de la sociedad que se legitima por un sistema que los invisibiliza, regidos por patrones jerárquicos excluyentes, discriminadores y patriarcales como estándares a seguir.

Por último, en la actualidad se hace necesario comprender y dar reconocimiento a la participación laboral de las mujeres, después de muchos años de pasividad e indiferencia. Una serie de cuestionamientos surgen ante los recortes laborales: las limitaciones de los derechos laborales, la inestabilidad laboral, el sueldo mínimo, la desigualdad de los salarios, el no reconocimiento del trabajo doméstico adherido a una constante incertidumbre de mejorar el plan de vida de las mujeres y de los hombres, del día a día, que se expresan por medio de una serie de movilizaciones 
de diferentes grupos, colectivos que inducen a retomar y revivir el interés por la situación laboral, como fue el caso de la movilización de los jóvenes ante la llamada Ley Pulpín. Por otro lado, las mujeres vienen demandando reconocimiento sobre sus cuerpos, su sexualidad y libertad de ocupar los espacios públicos, sin acoso callejero y libres de agresiones, vivir sin actos de violencia que desemboquen en feminicidios, que se respete la ley de cuotas en su participación política y acceder a sus derechos como ciudadanas sin exclusión por género.

En relación con la inserción laboral de las mujeres peruanas, se podría decir que han ganado una relativa presencia, reflejada en la cantidad de mujeres incorporadas en la PEA, sin profundizar en la calidad o las condiciones de bienestar como son verdaderamente incorporadas las mujeres en la estructura social y en las políticas del Estado. Todavía persiste la invisibilidad del trabajo de las mujeres en los hogares, ya que no se las considera en el PBI como parte de las cifras oficiales de los censos, y tampoco existe un registro que contabilice el trabajo informal de las mujeres en la economía. Todo ello dificulta el desarrollo de las investigaciones que expliquen la realidad laboral de las mujeres, porque se presenta la carencia o limitación de registros de fuentes que sean soportes para futuras investigaciones, y relegan los vacíos que confronta la investigadora o el investigador.

\section{Las medidas velasquistas en relación con las mujeres}

Durante el gobierno de Juan Velasco Alvarado se establecieron medidas reformistas vinculadas a la participación de las mujeres. La Junta Militar partió con la urgencia de buscar soluciones ante las desigualdades sociales: «cuando los militares encabezados por el general Velasco llegaron al poder, el tema de las desigualdades pasó a ser un punto clave de la agenda política» (Zapata y Rojas, 2013, p. 122).

El régimen velasquista vio la necesidad política de reflexionar y solucionar la situación de las mujeres peruanas. Les asignó el lugar que les corresponde y las hizo ejercer plenamente sus derechos. Además, les otorgó la dignidad como ciudadanas dentro de la formación de la nueva sociedad en todas sus instituciones.

El trabajo que fomentó el velasquismo sobre las mujeres se vio como iniciativa en sus discursos, que convocaron a hacer un trabajo en conjunto a hombres y mujeres en el proceso revolucionario. Ambos eran los responsables de llevar a cabo y garantizar el proceso con sus decisiones y participaciones ante las nuevas oportunidades del contexto y ser parte así de la lucha revolucionaria. Al respecto, la Oficina Nacional de Difusión del Sinamos (1972, tomo I, p. 76), escribe: 
Dentro del panorama cambiante de un proceso revolucionario verdadero, las mujeres y los hombres de este país deben comprender que las formas del pasado ya no pueden seguir prevaleciendo, porque es preciso labrar un camino distinto para un futuro distinto; que esa gran injusticia del ayer, en que muchos padecieron miseria y en que pocos disfrutaron holgura, no puede continuar.

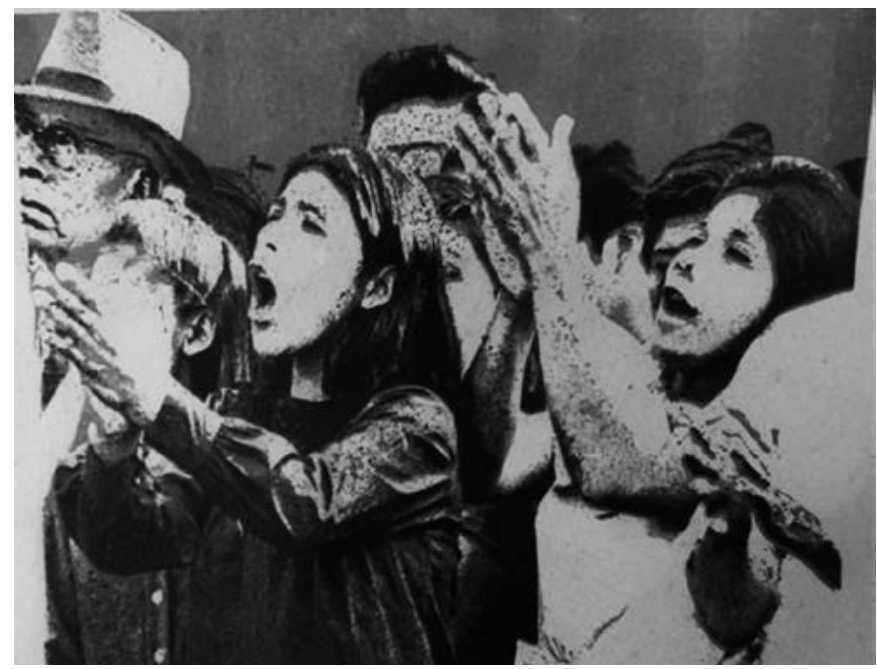

FIGURA 1. El 3 de octubre. ¡Todos a la plaza de Armas!, 1970, p. 11.

El velasquismo convocó e invitó a reformularse y comprenderse como sociedad, al sacar a la luz aquellos actores sociales ${ }^{3}$ no reconocidos ni valorados como tales. Las mujeres fueron parte de ello en el quehacer histórico de la sociedad peruana.

Nosotros queremos que la mujer peruana participe dinámica y creadoramente en todas las tareas de la transformación nacional. Que la mujer peruana ejercite la responsable y plena libertad a que tiene derecho. Y queremos también que nadie recorte sus derechos, que nadie olvide su papel decisivo como eje del hogar, que nadie la relegue a segundo plano (Alvarado, 1970).

Lo mencionado en el párrafo anterior nos permite concluir, primero, que el llamamiento discursivo de Velasco y su equipo de gobierno vio necesaria la participación conjunta de los hombres y las mujeres en desarrollar los cambios que estaban en marcha, como parte del proceso

3 Los actores olvidados y ausentes de la gestión directriz en el Perú estuvieron conformados por las mujeres, la juventud, los niños, los intelectuales, los científicos, los campesinos, los grupos populares y los artistas incorporados en el proceso revolucionario. 
revolucionario. Segundo, demandó de las mujeres desarrollar una serie de acciones como participar, tomar decisiones, comprometerse, trabajar y luchar. Tercero, el régimen buscó promover y establecer medidas que garantizaran la participación de las mujeres en la sociedad peruana y reducir toda discriminación que limitara sus oportunidades, hiciera peligrar sus derechos y afectara su dignidad. Por último, contradictoriamente ante la nueva forma de valorar el papel de las mujeres, se siguió resaltando su importancia en el ámbito del hogar.

Los discursos y las medidas políticas que el gobierno velasquista promovió para desarrollar cambios en la condición de las mujeres peruanas estuvieron bajo la responsabilidad de un grupo de mujeres intelectuales y profesionales que buscaron concientizar, organizar y hacer participar principalmente a las mujeres de los sectores urbano-marginales y así mejorar sus situaciones como ciudadanas y trabajadoras. Esta tarea se vio limitada al no reconocerlas como tales (por ejemplo, en el caso del ámbito agrario a las mujeres campesinas).

Las medidas políticas impulsadas por el velasquismo para las mujeres sentaron una base embrionaria institucional que conlleva a una serie de interrogantes. ¿Qué tan orgánicas fueron esas medidas políticas del gobierno velasquista en relación con las mujeres? ¿En qué medida se vieron concretadas las medidas políticas promovidas por el velasquismo en cuanto a la situación de las mujeres, particularmente en lo laboral?

Los lineamientos políticos del régimen sobre la condición de las mujeres fueron las siguientes:

1. En el punto 23 del Plan Inca se estableció la igualdad de derechos y obligaciones entre hombres y mujeres, es decir, acceder a sus derechos ciudadanos en los ámbitos familiar, político, educativo y laboral. Estas medidas permitieron propiciar la participación de las mujeres en todas las actividades y cargos en la revolución y en las decisiones. También promovió en las mujeres acceder a una educación cívica, como ideal a ejecutarse para que pueda ejercer sus derechos y deberes. Además, buscó eliminar todo acto discriminatorio que limitara el acceso a oportunidades, derechos y dignidad como mujeres.

2. En el ámbito educativo, la Ley General de la Educación, en su artículo 11, posibilitó la creación del Comité Técnico de Revaloración de la Mujer (Cotrem) ${ }^{4}$, que permitió:

- Acceder, reunir, incluir y abrir las posibilidades de estudios en un mismo espacio a hombres y mujeres en la educación secundaria y superior.

4 En 1973 se publicó el reglamento de la Ley General de Educación, sobre la Revaloración de la Mujer, pero fue marginado por no contar con un respaldo económico para su ejecución. 
- Reducir gradualmente el analfabetismo en hombres y mujeres.

- Impulsar la coeducación o educación mixta a través de la capacitación técnica impartida a las mujeres, por medio de una nueva educación familiar que promovía la compartición de tareas y responsabilidades domésticas entre hombres y mujeres. Además, concientizar a hombres y mujeres sobre la condición, la situación social, los derechos y la participación de las mujeres.

3. En el ámbito agrario, la reforma agraria excluyó a las mujeres en la distribución y posesión de las tierras y en el acceso a créditos como campesinas, ya que no se las reconoció como trabajadoras independientes $y$, por ende, como beneficiarias directas de las tierras. Solo se beneficiaron las mujeres supeditadas al perfil y al amparo masculino del padre u esposo, que fueron reconocidos como beneficiarios directos: «[en] la Ley de Reforma Agraria de 1974 se margina a la mujer como posible adjudicataria directa de unidades agrícolas reconociéndosele este derecho solo al fallecer el cónyuge o conviviente y mientras el hijo no cumpla 18 años» (Gil, Cordano, Moscoso, Tallada y Villar, 1993, p. 180).

4. En materia jurídica, el 30 de setiembre de 1969 se dio la Reforma del Código Civil, con la promulgación del Decreto Legislativo 17838, que obligó a las mujeres a intervenir en los contratos referentes al patrimonio matrimonial y se amparó los derechos de propiedad de las mujeres en unión de hecho o convivientes.

5. La Ley de Reforma de la Prensa (1974), por medio del Decreto Ley 29680, posibilitó al Estado tener el control de los contenidos e imágenes de los diarios que previamente fueron sometidos a revisión ante la Oficina Nacional de Informaciones. Con ello garantizó contenidos que no afectaran la dignidad de las mujeres en los medios de comunicación y permitió estar bajo los parámetros de la revolución. Previamente a la Ley de la Reforma de la Prensa, en 1969 se emitió el Decreto Ley 18075, reflejado en el Estatuto de la Libertad de Prensa, que reglamentó y condicionó los aspectos básicos de la prensa.

6. La Comisión Nacional de la Mujer Peruana (Conamup) estuvo conformada en su estructura interna por diversas comisiones, una de las cuales, la Comisión Mujer, Empleo y Población, permitió:

- Crear e incorporar a las organizaciones de mujeres presentes en los campos económico, productivo y político.

- Incorporar a las instituciones femeninas y garantizar sus acciones, decisiones, intervenciones en la sociedad y en la empresa.

7. Por último, el 31 de diciembre de 1974 se estableció el Año de la Mujer Peruana, por medio de la Resolución Suprema 0243-74-PM/ONAJ, que permitió: 
- El reconocimiento de las mujeres como actoras sociales.

- Ser una base legal que permitiera, gradualmente, cambiar la situación de las mujeres incentivando su desarrollo y participación, por medio de formulaciones políticas, y establecer un nuevo orden económico que las incorporara en el desarrollo y la participación productiva del país.

\section{La participación laboral de las obreras en la industria textil}

Las fábricas textiles de la década de 1970 fueron varias en Lima y provincias, pero detallaremos brevemente algunas de ellas que involucraron a las obreras en su masa laboral.

En Lima se ubicó la fábrica textil Lolas, que se caracterizó por ser una industria desarrollada y abastecida de una maquinaria moderna de alto nivel tecnológico. Desarrolló una mayor productividad, dio un mejor aprovechamiento de los recursos humanos, mejoró los métodos de trabajo que conllevó a una reducción de los costos de producción y, por ende, obtuvo productos a menores precios, de mejor calidad, y logró el acceso de mayores beneficios. También buscó establecer un sistema de incentivos al obrero que no radicó en trabajos por jornal su desarrollo fabril: «Los estudios de mejoras de métodos [...] unidos a una medición precisa de estándares de tiempo basados en los nuevos métodos de trabajo, han permitido aumentar la eficiencia en más de un 60\%, además de aumentar el rendimiento de la mano de obra considerablemente. [...] ha podido especializarse en una labor específica [...]» (Lolas una industria peruana como las mejores del mundo, 1968). Las condiciones laborales que brindó a sus trabajadores se basaron en el abastecimiento de guantes protectores y las sillas especiales acorde al cuerpo; asimismo, evitó contraer dificultades al buen desempeño e incentivó que tras cumplirse el $70 \%$ del trabajo se tuviera la opción de regresar a casa. Los trabajadores de la industria Lolas fueron los mejores pagados en la industria textil. Cumplieron con los estándares internacionales para competir en el mercado externo.

\section{La capacitación técnica de las obreras textiles}

Los centros de capacitación técnica a los que accedieron las obreras estuvieron compuestos por el Centro de Capacitación Industrial y Formación (Cenif), escuelas técnicas industriales femeninas e institutos industriales femeninos. A continuación, se explica cada uno con mayor detalle:

Cenif prepara técnicamente a grupos de mujeres jóvenes que quieran capacitarse como operarias de la industria textil [...]. Cuando termina su aprendizaje se coloca inmediatamente con el salario de operaria calificada. [...] aporta gratis los útiles a las alumnas: cuando rompen agujas no las cobra, a pesar de que son muy caras. [...]. 
Paralelamente a la preparación material, durante los dos años que dura el curso, reciben un mínimo de cultura, educación moral y sindical. Estos principios son impartidos teniendo en cuenta la justicia, el respeto y el cumplimiento de leyes vigentes de trabajo, que norman derechos y obligaciones de los trabajadores. Algunas fábricas textiles obsequien parte de las fibras que se necesitan para el aprendizaje del tejido y piden con antelación operarias, aun antes que egresen las promociones (E. de G., 1969, p. 24).

En relación con las escuelas técnicas industriales, se registró:

Las escuelas técnicas industriales femeninas [...] vienen cumpliendo una elevada función social y pedagógica, en la formación de la juventud escolar que se prepara en determinados trabajos técnicos que puede realizar en cuanto egresa del colegio [...]. La industria del vestido ha tomado gran injerencia en todas las escuelas industriales de mujeres. [...]. Dos puntos importantes se advierten en la enseñanza técnica de corte y confección: la perfección de los atuendos confeccionados y el que la juventud femenina se interesa por esa profesión técnica de efectivo rendimiento económico (E. de G., 1970. p. 20).

Por último, los Institutos de Promoción y Educación Técnica (IPET) fueron medios que permitieron la formación técnica de las mujeres para su ingreso a la actividad textil como medio laboral.

de acuerdo con un convenio suscrito con IPET, tendrá a su cargo el total equipamiento del centro industrial. En él, las madres de familia, bajo la dirección de expertos, realizarán una amplia gama de confecciones que posteriormente se pondrá a la venta en los mercados de Lima (Gran centro industrial femenino inicia labores con 40 máquinas, 1969, p. 6).

\section{Características de las obreras textiles en la industria}

La situación de las obreras en este periodo velasquista se caracterizó por lo siguiente:

- Tuvieron una previa capacitación de sus labores, a raíz de sus responsabilidades en el hogar, y lograron transferir sus habilidades y aprendizajes del mundo fabril.

- En su mayoría, fueron migrantes, como toda la fuerza laboral.

- Su incorporación como masa laboral en las fábricas fue en menor cantidad a la demanda.

- Reiterativamente desempeñaron una actividad acorde a la alusión social de «feminidad».

- Se les asignó actividades con fuerte grado de estereotipos, consideradas usualmente como labores de «poca fuerza física» y «simples». 
- Estuvieron supeditadas a una inestabilidad laboral por medio de los contratos y expuestas a una precariedad en las condiciones laborales (horas de trabajo, jornadas laborales, puestos de trabajo, estabilidad y formación laboral, acoso sexual). También fue limitada su seguridad o protección social (pensiones de salud).

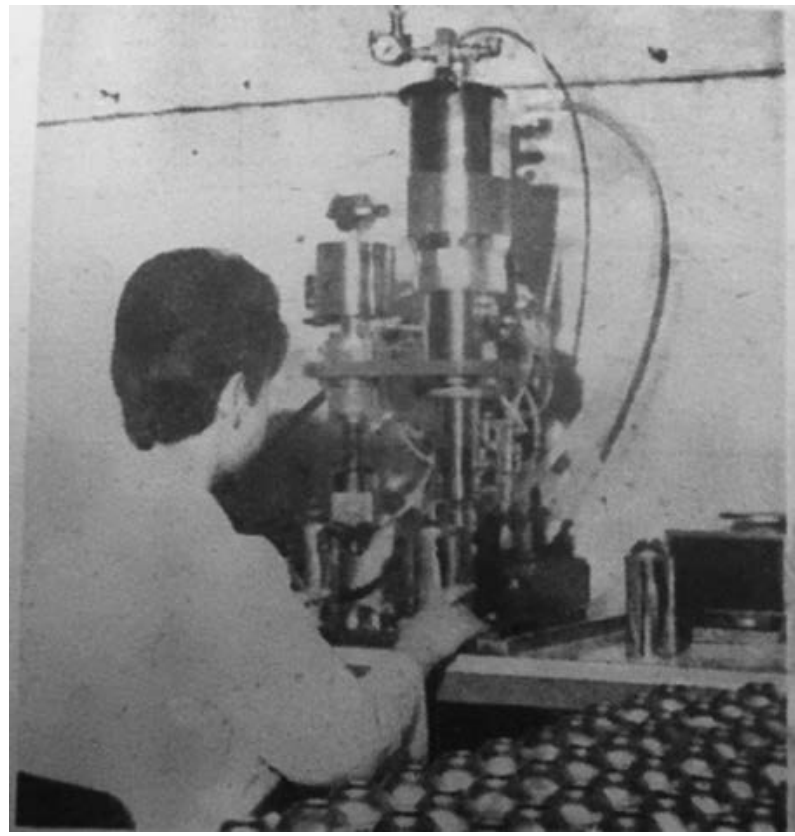

FIGURA 2. Inauguran planta envasadora de aerosoles, 1968, p. 17.

\section{Las razones que condicionaron el estado laboral de las obreras textiles}

La primera razón fue su condición de género. A partir de la herencia de construcciones socioculturales que se han elaborado en el transcurrir del tiempo, se ha considerado y valorado a las mujeres según sus labores en el hogar, pero no como una actividad que demanda trabajo, sino como una acción innata y necesaria que complementa. Si sus labores se realizaban fuera de casa, como trabajadoras remuneradas, estas fueron usualmente subestimadas, y sus prácticas se calificaron como actividades fáciles, complementarias, automáticas, ejecutadas acorde a su naturaleza femenina, que exigía menor resistencia y menor fuerza física. También fueron calificadas como labores que demandaron de ellas una menor formación, menor instrucción, menor calificación y menor productividad ante la falta de experiencia laboral.

La industria se universaliza. Al igual se ven mujeres desplazarse cada mañana a sus centros laborales [...]. En todas sus faenas pone su 
subconsciente maternal. En todo trabajo se esmera con cuidado, debido a la cualidad de ama de casa que posee. La mujer es símbolo del regazo que cobija al niño. Y por ello es que en todas sus labores utilitarias vierte, sin darse cuenta, ese sentimiento de amor innato en ella. [...]. En todas las naciones sin excluir ninguna, manos femeninas están ligadas a la industria, no como rivales del hombre [...] sino dentro del paralelismo para alcanzar un fin común: aportar potencias físicas y morales para el progreso de la economía estatal y adquirir los medios de vida familiar (E. de G., 1968, p. 24).

En estos tiempos en que el hombre puede apreciar que la mujer no pierde su delicadez femenina, tomando parte activa en todas las actividades humanas (Hombres y mujeres se organizan con fines de educación masiva, 1968, p. 24).

La segunda razón fueron las características de sus actividades como obreras, que se supeditaron a una poca movilización en el área fabril y la poca relación con las herramientas tecnológicas (uso y control de las máquinas), ya que se las relegó a las tareas repetitivas y manuales, que exigían destreza y minuciosidad visual.

La primera y la segunda razón, interrelacionadas, fueron el soporte para argumentar y justificar las condiciones laborales que rigieron a las obreras: bajas remuneraciones, mayores jornadas laborales, ocupaciones segregadas, exposición a un escenario de acoso sexual por parte de sus compañeros de trabajo y dueños de la fábrica. También nos permiten comprender la supeditación a reducidos beneficios laborales, como el seguro, la pensión, la carencia de una protección social, la poca ejecución de los derechos laborales, la precaria estabilidad laboral, las limitadas capacitaciones, las pocas oportunidades para lograr un ascenso laboral y el acceso a puestos de trabajo con prácticas desiguales y discriminatorias.

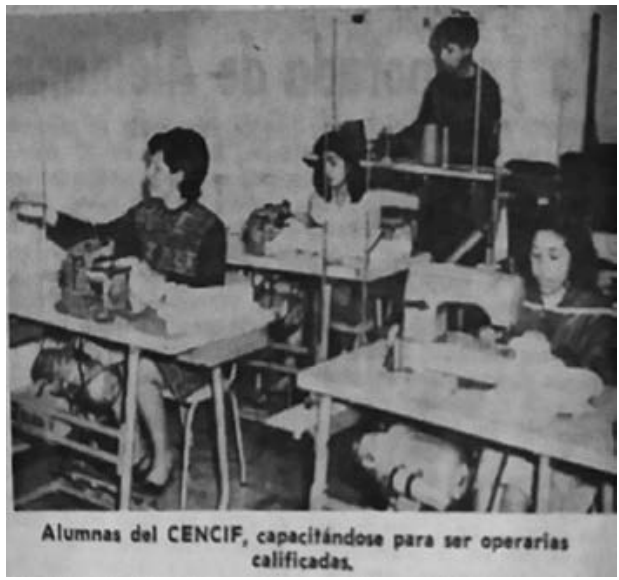

FIGURA 3. E. S. S. de G., 1971, p. 22. 


\section{La participación política de las obreras en la industria textil: sindicatos y comunidades industriales}

Durante el velasquismo un número reducido de obreras participó en los sindicatos textiles. Esta historia sindical no ha sido documentada, debido a una herencia historiográfica que tradicionalmente las ha excluido y no las representan en las investigaciones como actoras sociales.

Deben agregarse también las limitadas miradas y la falta de interés de la comunidad académica de insertarlas. A pesar de haber sido un número pequeño, al igual que los obreros, no se vio necesaria su inserción en la historia, lo que conllevó a una limitada comprensión del movimiento sindical.

Las intervenciones de las obreras muestran un interés en participar de manera directa e indirecta en acuerdos, organizaciones, reuniones, etc., de carácter político en el sindicato. Por ejemplo, la fábrica Beauty Form formó el Sindicato de Trabajadores en Confecciones Beauty Form, integrado por obreras, que desarrollaron una huelga indefinida debido a una disputa en la dirección del sindicato, bajo control de un comité de trabajo de dirección aprista de la CTP. Para ello, utilizaron la olla común como mecanismo de lucha y resistencia de la huelga. El resultado de la huelga fue el triunfo de Olga Burgos en la dirección sindical como secretaria general del sindicato, partidaria de la CGTP y acompañada en su equipo por una serie de obreras.

La olla común viene haciendo más común [...]. Todos los días entre la una y las dos de la tarde, en una calle de Breña, toman sus alimentos las heroicas trabajadoras - más de 150- del combativo Sindicato de Confecciones. [...]. La Federación de Confecciones se ha solidarizado con esta lucha [y ha organizado] una huelga general indefinida (Sin tregua, 1973, reverso de la p. 11).

Olga Burgos fue ratificada por abrumadora mayoría en su cargo de la Secretaría General del Sindicato de Trabajadores en Confecciones Beauty Form. También se reafirmaron como dirigentes de este organismo Ludvinda Yunkor, Ruth Tafur, entre otras. Después de 40 días de heroico combate huelguístico, derrotaron en todos los terrenos a Olinda López y su lista patronal (Sin tregua, 1973, p. 11).

El resultado final que culminó con el triunfo del Sindicato de Trabajadores en Confecciones Beauty Form se debió a su afiliación a la Federación de Trabajadores en Confecciones y Similares del Perú, base de la CGTP, que adoptó la línea del sindicalismo clasista y respaldaron al proceso revolucionario velasquista y las demandas laborales de clase. Se repuso a Aída Idoña como presidenta de la comunidad industrial y como secretaria del sindicato a Olga Burgos. 
El Sindicato de Trabajadores de Confecciones Beauty Form derrotó a la CTP aprista y, consiguientemente, se afilió a la Federación de Trabajadores en Confecciones y Sindicales del Perú, base de la CGTP. Se inició así una etapa nueva en la lucha de este sindicato. En efecto, desde hace 15 años estuvo bajo la orientación del llamado «sindicalismo libre», reformista, que propugnó la convivencia entre el patrón y el obrero. Ahora el sindicato siguió la concepción clasista que pugnó por liquidar la explotación del hombre por el hombre. Y en consecuencia con ello, desarrolló, a través de la óptica de la CGTP, una lucha reivindicativa que abre cauce hacia tal objetivo.

En 15 años, la CTP solo consiguió «aumentos» salariales que fluctuaron entre los dos y cuatro soles anuales y ninguna otra mejora [...] siempre la dirigencia aprista coincidía con la empresa afirmando que esta no obtenía mayormente ganancias [...] Olga Burgos, Ludvinda Yunkor y Ruth Tafur, dirigentes del sindicato: «Nosotros hemos comprendido en estos días de huelga, que con nuestra lucha de inmediato solo conseguiremos algunas mejoras económicas, meros paliativos, pero aun así necesarios. Pero, pensamos, lo principal es que con nuestra acción de clase nos estamos integrando de hecho a la lucha del conjunto de la clase obrera y del pueblo consciente de nuestra patria, contra la explotación de la oligarquía y el imperialismo que nos oprime; estamos contribuyendo al avance victorioso del proceso revolucionario que dirige el Gobierno Revolucionario de la Fuerza Armada. Este trabajo de conciencia en el seno del sindicato de Beauty Form es lo más importante que los 20 o 30 soles de aumento que indudablemente obtendremos (Sin tregua, 1973, reverso de la p. 11).

Por otro lado, se suma la participación sindical de las obreras textiles de la fábrica de Texoro, con accionar y situaciones diferentes durante el velasquismo.

Durante dos horas y media un grupo de 70 obreras de la fábrica de confecciones Texoro ocuparon la Basílica de la Merced, en actitud de protesta por el cierre de la fábrica. [...] Las obreras al ingresar a las 8 p. m., cerraron la puerta principal de la iglesia, así como las puertas laterales, lo que obligó a los custodios del orden a ingresar por la puerta del mencionado plantel. El intendente de Lima, teniente coronel EP Alberto Carmona, se hizo presente en el lugar, pero las obreras mostraron su determinación de permanecer en el sitio, lo que obligó al R. P. Farfán a solicitar el desalojo por medio de la policía [...] Cumpliendo este trámite, la policía llevó a cabo el desalojo de las obreras con toda energía, las que fueron sacadas por la puerta del Colegio La Merced, que da al jirón Carabaya a las 10:30 p. m. [...] Una vez en la calle, las obreras se retiraron a sus domicilios (Obreras ocuparon templo de La Merced en protesta por cierre de fábrica, 1969, p. 19). 
El sindicato de la fábrica Texoro estuvo a cargo de la secretaria general Ana Villafana, que mostró una posición clasista y consideró a la fuerza sindical como el motor de la organización y de consolidación de la lucha obrera.

la secretaria general del Sindicato de Texoro, Ana Villafana, condenó acremente la conducta de algunos desclasados y pequeños grupos divisionistas «que atentan contra la unidad clasista y ponen en peligro los intereses de los trabajadores».

Luego, hizo un recuento de la lucha de la Federación de Trabajadores en Confecciones, que gracias a su unidad lograron arrancar el reconocimiento oficial y derrotar la provocación patronal. Reafirmó su aval a la CGTP, que «siempre ha estado junto a nosotros, respaldando nuestras justas reivindicaciones» (Oradores denunciaron conjura patronal, 1973, p. 7).

Aparte de los sindicatos, las comunidades industriales albergaron en su estructura interna la organización de comités de trabajadores, integrado por obreras. "Se creó la comunidad laboral como mecanismo de participación de los trabajadores en la propiedad, gestión y utilidades de las empresas» (Barboza, 2013, p. 56).

La participación de obreras en las comunidades industriales se materializó en la fábrica de pantalones Cónsul, en 1970. Su comité organizador estuvo conformado por cinco hombres y cinco mujeres, y su presidenta fue la obrera Victoria Fuentes Álvarez, de 20 años.

Victoria Fuentes trabaja desde los 17 años en la misma fábrica [...] tuvo que trabajar desde esa edad porque ayuda al sostenimiento de una familia de nueve hermanos [...] es jefa de Costura y tiene a su cargo a 20 obreras en la fábrica. Continúa hablando de la necesidad de participar de todos los trabajadores — hombres y mujeres - en forma activa en la instalación de comunidades industriales. «Nos beneficia a todos sin distinción de sexos». Agrega: «y por lo tanto las mujeres también estamos obligadas a hacer cumplir nuestros derechos». Victoria cree firmemente en la igualdad de derechos de la mujer y que solo luchando, al igual que el hombre, se puede conseguir una prosperidad a corto plazo para la clase trabajadora y para el país. Ella cree que la mujer está en las mismas condiciones que el hombre, para asumir responsabilidades (Victoria Fuentes a los 20 años preside primera comunidad, 1970, p. 21).

Las obreras que participaron en el espacio sindical y en la comunidad industrial lograron un desarrollo personal, tuvieron seguridad, consiguieron mayor independencia, generaron espacios de socialización, adquirieron conocimientos, alcanzaron medios, conquistaron el respeto por sus derechos como trabajadoras y, por último, lograron una protección social. 


\section{Conclusiones}

La participación laboral de las obreras textiles fue resultado de un proceso de industrialización que se inició con fuerza los años previos a la instauración del régimen velasquista. Este régimen buscó promover y desarrollar las economías del país por medio de una serie de medidas proteccionistas. Sin embargo, las medidas implementadas fueron desventajosas y no tuvieron un impacto positivo sobre la condición laboral en la rama textil.

La participación política de las obreras textiles se realizó en el espacio sindical y en la comunidad industrial. En estos espacios expresaron sus reclamos, recurriendo a la toma de locales y ejerciendo su derecho a la huelga de hambre, con el objetivo de conquistar sus demandas laborales. A pesar de que enfrentaron situaciones que limitaban su participación política, desarrollaron un mayor sentido de independencia y seguridad, que les permitió integrar nuevos espacios de socialización y obtener una formación política sobre sus derechos laborales.

En suma, el papel que desempeñaron las obreras en la industria textil fue diverso y monótono. Las actividades laborales exigieron de ellas cualidades supuestamente «femeninas», como la delicadeza y la habilidad manual, que, en conjunto, las ayudaron a desempeñar tareas repetitivas y generar un valor agregado del producto. De este modo, se garantizó el abastecimiento y el dinamismo del mercado interno, que brindaron ingresos económicos a la industria, al Estado y a ellas como trabajadoras, y contribuyeron al mantenimiento del hogar y la alimentación de los hijos.

\section{Contribución de autor}

La autora ha participado en la concepción, la recolección de datos, la redacción y la aprobación de la versión final del artículo.

\section{Fuente de financiamiento}

Autofinanciado.

\section{Conflicto de intereses}

La autora declara no tener conflictos de interés. 


\section{FUENTES DE INFORMACIÓN}

\section{Diarios}

Alvarado, V. (4 de octubre de 1970). El futuro no lo haremos mañana... ¡Lo haremos ahora! Expreso, p. 4.

Beauty Form por la senda del triunfo. (15 de noviembre de 1973). Unidad, reverso de la p. 11.

E. de G. (21 de enero de 1970). La técnica de la confección del vestido en centros industriales y proyección en terreno laboral. El Comercio, p. 20.

E. de G. (24 de octubre de 1968). Esfuerzo femenino contribuye al desarroIlo industrial del mundo. El Comercio, p. 24.

E. de G. (3 de octubre de 1969). La técnica industrial es factor importante para el desarrollo de la economía y grandeza nacional. El Comercio, p. 24.

E. S. S. de G. (26 de febrero de 1972). Centro de capacitación técnica adiestra a operarias textiles. El Comercio, p. 22.

El 3 de octubre. ¡Todos a la plaza de Armas! (27 de setiembre de 1970). Estampa, Expreso, p. 11.

Gran centro industrial femenino inicia labores con 40 máquinas. (18 de mayo de 1969). El Comercio, p. 6.

Hombres y mujeres se organizan con fines de educación masiva. (16 de noviembre de 1968). El Comercio, p. 24.

Inauguran planta envasadora de aerosoles. (11 de octubre de 1968). Expreso, p. 17.

Lolas una industria peruana como las mejores del mundo. (29 de enero de 1968). Expreso, p. 15.

Obreras ocuparon tempo de La Merced en protesta por cierre de fábrica.

(12 de diciembre de 1969). El Comercio, p. 19.

Oradores denunciaron conjura patronal. (3 de mayo de 1973). Unidad, p. 7.

Sin tregua. (22 de noviembre de 1973). Unidad, p. 11 y reverso de la p. 11.

Victoria Fuentes a los 20 años preside primera comunidad. (16 de setiembre de 1970). Expreso, p. 21. 


\section{REFERENCIAS BIBLIOGRÁFICAS}

Barboza, M. (2013). La liberación de la mujer en el Perú de los 70: una perspectiva de género y estado (tesis de magíster en Ciencias Sociales, especialidad de Género, Sexualidad y Políticas Públicas). Universidad Nacional Mayor de San Marcos, Lima.

Balbi, C. (1989). Identidad clasista en el sindicalismo, su impacto en las fábricas. Lima: Desco y Centro de Estudios y Promoción del Desarrollo.

Barrig, M. (1985). Mujer, trabajo y empleo. Lima: Asociación de Defensa y Capacitación Legal.

Barrig, M. (1986). Las obreras. Lima: Mosca Azul Editores y Asociación de Defensa y Capacitación Legal.

Sinamos (1972). Velasco. La voz de la revolución. Discursos del presidente de la República, general de división Juan Velasco Alvarado, 1968-1970. Tomos I-II. Lima: Participación.

Zapata, A. y Rojas, R. (2013). ¿Desiguales desde siempre? Miradas históricas sobre la desigualdad. Lima: Instituto de Estudios Peruanos.

Recibido: 20/7/2019

Aceptado: 4/11/2019 